University of South Florida

DIGITAL COMMONS Digital Commons @ University of @ UNIVERSITY OF SOUTH FLORIDA South Florida

10-1-2015

\title{
Analysis of Built Environmental Features and Effects on Freight Activities
}

CUTR

Follow this and additional works at: https://digitalcommons.usf.edu/cutr_nctr

\section{Recommended Citation}

"Analysis of Built Environmental Features and Effects on Freight Activities," National Center for Transit Research (NCTR) Report No. CUTR-NCTR-RR-2015-04, Center for Urban Transportation Research, University of South Florida, 2015.

DOI: https://doi.org/10.5038/CUTR-NCTR-RR-2015-04

Available at: https://scholarcommons.usf.edu/cutr_nctr/26

This Technical Report is brought to you for free and open access by the National Center for Transit Research (NCTR) Archive (2000-2020) at Digital Commons @ University of South Florida. It has been accepted for inclusion in Research Reports by an authorized administrator of Digital Commons @ University of South Florida. For more information, please contact digitalcommons@usf.edu. 


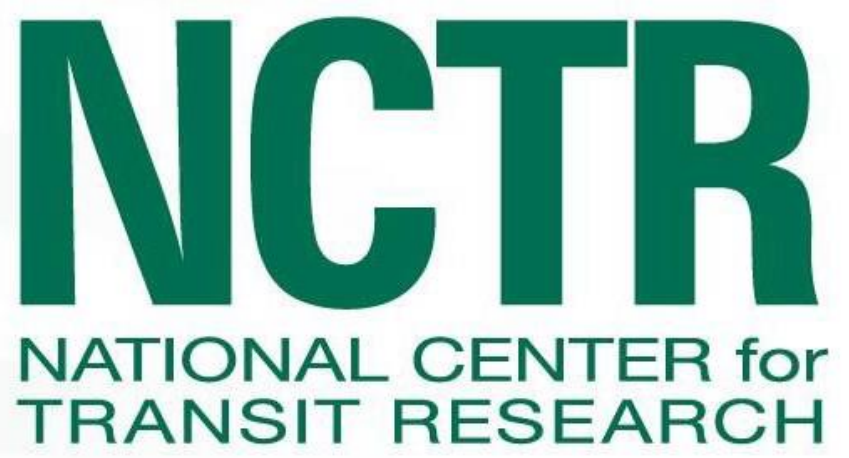

\section{Analysis of Built Environmental Features and Effects on Freight Activities}

\section{October}

2015

PROJECT NO. 2117-9060-02-C

PREPARED FOR

National Center for Transit Research (NCTR) 


\section{Disclaimer}

The contents of this report reflect the views of the authors, who are responsible for the facts and the accuracy of the information presented herein. This document is disseminated under the sponsorship of the Department of Transportation University Transportation Centers Program and the Florida Department of Transportation, in the interest of information exchange. The U.S. Government and the Florida Department of Transportation assume no liability for the contents or use thereof.

The opinions, findings, and conclusions expressed in this publication are those of the authors and not necessarily those of the State of Florida Department of Transportation. 


\begin{abstract}
Urban
Transportation Center

THE URBAN TRANSPORTATION CENTER AT

THE UNIVERSITY OF ILLINOIS AT CHICAGO

\section{Analysis of Built Environmental Features and Effects on Freight Activities}

October 2015

UIC 2117-9060-02-C

Prepared For

National Center for Transit Research

Center for Urban Transportation Research

University of South Florida 


\title{
Analysis of Factors Affecting Truck Parking Violation Frequency in Urban Areas
}

\author{
Kazuya Kawamura \\ College of Urban Planning and Public Affairs, University of Illinois, Chicago \\ 412 S. Peoria St., Chicago, IL 60607-7065 \\ Phone: (312) $413-1269$ \\ FAX: (312) $413-2314$ \\ E-Mail: kazuya@uic.edu \\ P.S. Sriraj \\ Urban Transportation Center \\ College of Urban Planning and Public Affairs, University of Illinois at Chicago \\ 412 S. Peoria St., Chicago, IL 60607-7065 \\ Phone: (312) $413-7568$ \\ FAX: (312) 413 - 0006 \\ E-mail: sriraj@uic.edu \\ Havan Raj Surat \\ Urban Transportation Center \\ College of Urban Planning and Public Affairs, University of Illinois at Chicago \\ 412 S. Peoria St., Chicago, IL 60607-7065 \\ Phone: (312) 996-3221 \\ FAX: (312) 413 - 0006 \\ E-mail: havanraj@uic.edu \\ Martin Menninger \\ Urban Transportation Center \\ College of Urban Planning and Public Affairs, University of Illinois at Chicago \\ 412 S. Peoria St., Chicago, IL 60607-7065 \\ Phone: (312) 996-2667 \\ FAX: (312) 413 - 0006 \\ E-mail: mmenni2@uic.edu
}




\section{Technical Report Documentation}

\begin{tabular}{|l|l|l|}
\hline $\begin{array}{l}\text { 1. Report No. } \\
\text { UIC 2117-9060-02-C }\end{array}$ & 2. Government Accession No. \\
\hline $\begin{array}{l}\text { 4. Title and Subtitle } \\
\text { Analysis of Built Environmental Features and } \\
\text { Effects on Freight Activities }\end{array}$ & $\begin{array}{l}\text { 5. Report Date } \\
\text { October 2015 }\end{array}$ \\
\hline $\begin{array}{l}\text { 6. Performing Organization Code } \\
\text { 7. Author(s) }\end{array}$ & $\begin{array}{l}\text { 8. Performing Organization Report No. } \\
\text { Urban Transportation Center } \\
\text { University of Illinois at Chicago } \\
\text { 412 S. Peoria Street, Suite 240 } \\
\text { Chicago, IL 60607 }\end{array}$ \\
\hline $\begin{array}{l}\text { 9. Performing Organization Name and Address } \\
\text { National Center for Transit Research } \\
\text { Center for Urban Transportation Research (CUTR) } \\
\text { University of South Florida } \\
\text { 4202 East Fowler Avenue, CUT100 } \\
\text { Tampa, FL 33620-5375 }\end{array}$ \\
\hline $\begin{array}{l}\text { 11. Contract or Grant No. } \\
\text { 10. Work Unit No. (TRAIS) }\end{array}$ \\
\end{tabular}

12. Sponsoring Agency Name and Address

13. Type of Report and Period Covered

Research and Innovative Technology Administration

U.S. Department of Transportation

Mail Code RDT-30, 1200 New Jersey Ave SE, Room E33

Washington, DC 20590-0001

14. Sponsoring Agency Code

\section{Supplementary Notes}

\section{Abstract}

A 2005 study by Han et al estimated that illegal parking of parcel delivery vehicles was the third leading cause of urban non-recurring congestion behind vehicle crashes and construction. However, very little has been done to investigate the causes of illegal parking by trucks and develop mitigation strategies. As an exploratory step toward addressing truck parking problems in urban areas, this study analyzed truck parking citation data in Chicago to identify factors that affect concentration of high density of violations. Analysis of hot spots using the geographic information system (GIS) showed that parking problems are generally worse within or near the downtown and become less prevalent toward the outer perimeter of the city. However, it was also found that truck parking does not seem to be a serious issue in the part of the city that has been home to industrial sites for a long time. The regression analysis revealed that truck parking problems can be exacerbated by the concentrations of food businesses in newly developed neighborhoods with low density of vehicles owned by its residents. The finding underscores the importance of land use plan and urban and streetscape designs that takes into account trucks in the neighborhoods that may not seem to generate intense truck activities. The study also found that alleys could alleviate some of the truck parking problems although their effect is relatively modest.

\begin{tabular}{|l|l|l|l|}
\hline $\begin{array}{l}\text { 17. Key Words } \\
\text { Freight, illegal parking, delivery vehicles }\end{array}$ & $\begin{array}{l}\text { 18. Distribution Statement } \\
\text { No restrictions }\end{array}$ \\
\hline $\begin{array}{l}\text { 19. Security Classification } \\
\text { (of this report) }\end{array}$ & $\begin{array}{l}\text { 20. Security Classification } \\
\text { (of this page) }\end{array}$ & $\begin{array}{l}\text { 21. No. of Pages } \\
19\end{array}$ & 22. Price \\
Unclassified & Unclassified & & \\
\hline
\end{tabular}


Metric Conversion

\begin{tabular}{|c|c|c|c|c|}
\hline SYMBOL & WHEN YOU KNOW & MULTIPLY BY & TO FIND & SYMBOL \\
\hline \multicolumn{5}{|c|}{ LENGTH } \\
\hline in & inches & 25.4 & millimeters & $\mathrm{mm}$ \\
\hline ft. & feet & 0.305 & meters & $\mathrm{m}$ \\
\hline yd. & yards & 0.914 & meters & $\mathrm{m}$ \\
\hline mi & miles & 1.61 & kilometers & $\mathrm{km}$ \\
\hline \multicolumn{5}{|c|}{ VOLUME } \\
\hline fl. oz. & fluid ounces & 29.57 & milliliters & $\mathrm{mL}$ \\
\hline gal & gallons & 3.785 & liters & L \\
\hline $\mathbf{f t}^{3}$ & cubic feet & 0.028 & cubic meters & $\mathrm{m}^{3}$ \\
\hline$y d^{3}$ & cubic yards & 0.765 & cubic meters & $m^{3}$ \\
\hline \multicolumn{5}{|c|}{ NOTE: volumes greater than $1000 \mathrm{~L}$ shall be shown in $\mathrm{m}^{3}$} \\
\hline \multicolumn{5}{|c|}{ MASS } \\
\hline oz. & ounces & 28.35 & grams & $\mathrm{g}$ \\
\hline lb. & pounds & 0.454 & kilograms & $\mathrm{kg}$ \\
\hline $\mathbf{T}$ & Short tons (2000 lb.) & 0.907 & $\begin{array}{c}\text { megagrams } \\
\text { (or "metric ton") }\end{array}$ & $\mathrm{Mg}($ or "t") \\
\hline \multicolumn{5}{|c|}{ TEMPERATURE (exact degrees) } \\
\hline${ }^{\circ} \mathbf{F}$ & Fahrenheit & $\begin{array}{c}5(F-32) / 9 \\
\text { or }(F-32) / 1.8\end{array}$ & Celsius & ${ }^{\circ} \mathrm{C}$ \\
\hline
\end{tabular}




\begin{abstract}
A 2005 study by Han et al estimated that illegal parking of parcel delivery vehicles was the third leading cause of urban non-recurring congestion behind vehicle crashes and construction. However, very little has been done to investigate the causes of illegal parking by trucks and develop mitigation strategies. As an exploratory step toward addressing truck parking problems in urban areas, this study analyzed truck parking citation data in Chicago to identify factors that affect concentration of high density of violations. Analysis of hot spots using the geographic information system (GIS) showed that parking problems are 10 generally worse within or near the downtown and become less prevalent toward the outer perimeter of the 11 city. However, it was also found that truck parking does not seem to be a serious issue in the part of the 12 city that has been home to industrial sites for a long time. The regression analysis revealed that truck 13 parking problems can be exacerbated by the concentrations of food businesses in newly developed 14 neighborhoods with low density of vehicles owned by its residents. The finding underscores the 15 importance of land use plan and urban and streetscape designs that takes into account trucks in the 16 neighborhoods that may not seem to generate intense truck activities. The study also found that alleys 17 could alleviate some of the truck parking problems although their effect is relatively modest.
\end{abstract}




\section{INTRODUCTION}

While nearly every driver can recall his/her experiences with frustrations caused by illegally parked delivery or service vehicles, there have not been many studies that actually examined their impacts. A study by Han et al (1) estimated that conservatively, illegal parking of parcel delivery vehicles is the third leading cause of urban non-recurring (i.e. not due to traffic volume) congestion behind crashes and construction. They estimated that total delay caused by illegally parked pick-up/delivery vehicles in large urban areas in the U.S. to be 500 million vehicle hours annually, costing some $\$ 10$ billion in lost time. Surprisingly, there have been very little efforts to reduce truck-related congestion in urban areas.

A study by Pivo (2) is the only example to our knowledge that examined the effects of built environment on truck operations. Pivo's research relied on the interviews and observations, conducted in Seattle, to develop some recommendations for improvements. His effort, however, focused on improving truck operations and did not investigate the cause of truck-related congestion. Some studies, e.g. a study of strategies aimed at improving truck operations in Washington, D.C. (3), developed recommendations for improving truck operations and mitigating truck-related congestions. The aim of those studies is to address specific issues that exist in their cities. As such, they do not provide systematic analysis of data that can identify causal factors of delivery truck-related congestion.

A recent study in New York City (4) developed models for truck parking demand $(5,6)$ and curb space availability using tax map and property information data. While the study is, to our knowledge, the only example of an academic effort to systematically examine demand-supply balance for trucks for a large urban area, the authors had to employ several key assumptions regarding deliveries per stop and service hours. Another recent study by Conway et al, (7) examined, using video recordings, frequency of conflicts between bicycles and trucks in New York City. They found that surprisingly, frequency of conflicts tends to be higher for areas with lower business densities. They attribute this phenomenon to the fact that the blocks that are occupied by a small number of large business establishments tend to experience more intense, and possibly more concentrated, truck activities.

While it is encouraging to see an increased interest in the topic of truck-related conflicts in urban areas, many knowledge gaps still remain. The aim of this paper is to present analyses of truck parking problems in urban areas using truck parking citation records in Chicago. The study strives to identify built environment and socioeconomic factors that are associated with the frequency of truck parking violations in Chicago. Parking citation data are effective indicators of truck parking problems and hot spots because they directly capture the presence of parking problems. One of the issues that arise with the use of parking ticket data is the potential variability in the level of enforcement effort. In this study, we use the density of parking violations given to passenger vehicles to account for the enforcement intensity.

\section{DATA}

The data for parking violations were obtained from the City of Chicago. City of Chicago is approximately $600 \mathrm{~km}^{2}$ in land area and home to 2.7 million people, inhabiting a total of 1.2 million housing units. Chicago is the third largest city in the U.S. by population. All the vehicles owned by a resident of Chicago must have a city registration sticker displayed on the vehicle. In 2011, approximately 1.3 million stickers were issued by the city. According to the Urban Mobility Report (8), Chicago ranks seventh in terms of overall severity of congestion. However, Chicago ranks third behind New York and Los Angeles areas in terms of average truck delay, reflecting its role as the major freight hub for the nation.

The dataset obtained for this study includes all the parking citations given in the city during a 12-month period between September 1, 2011 and August 31, 2012. The descriptive analyses provided in the following section are based on this 12-month data; however, for the hot spot and the regression analyses, 
we extracted the citations that were issued during July and August of 2012 to limit the number of data points that needed to be geocoded in geographic information system (GIS). The July-August 2012 dataset contains a total of 17,680 citations attributed to trucks.

The socioeconomic variables used in the regression analysis are obtained from a combination of sources that include US Census of Population, US Economic Census, proprietary consumer survey databases, and Dun and Bradstreet business database. All the variables are aggregated at the Census block group level. All the data are from 2012 except for the vehicle availability, which is from 2011.

\subsection{Descriptive Analysis}

Trucks weighing over 4,500 lbs are not allowed to park on city streets in Chicago unless they are engaged in servicing or loading/unloading activities or display a residential parking permit (different from the city sticker). Furthermore, commercial vehicles are not allowed to travel on designated "boulevards" in Chicago.

Table 1 shows the breakdown of tickets issued during the 12-month period by types of violations. It should be noted that the dataset only includes citations given during the parking enforcement activities, and other types of violations given, e.g. Equipment, Operation, and Seatbelt, shown in the table were incidentally included in the dataset. In some cases, those other violations are given in addition to a parking citation. For example, if a truck being parked illegally on a street has a faulty equipment, then the enforcement officer may issue a parking ticket and a citation for "equipment". Those citations were excluded from the dataset before the hot spots and the regression analyses that will be discussed in Section 3.

For the one year period, truck parking tickets accounted for a total of $\$ 8.2$ million in fines. The average amount of fine was $\$ 65$ per violation/citation. As shown, a large share, $29 \%$, of the total cases are attributed to "Vehicle Type Prohibited". "Vehicle Type Prohibited" is often used by the parking officers in cases where a truck weighing over $4,500 \mathrm{lbs}$ is found parked on a city street without engaging in loading/unloading activities. Vehicle Type Prohibited citation can also be issued to vehicles that are parked on any of the boulevards.

Expired meter and parking permit violations account for $23.5 \%$ of total citations. Parking permit system and parking meters are used in limited areas near the central business districts, heavy commercial areas, and dense residential areas, all of which contribute to a high-stress environment for trucks and passenger vehicles alike. Residents of a block can submit a petition to establish a residential parking permit when certain conditions are met (9). Residential permit system is designed to prevent vehicles that do not belong to the area residents from using on-street parking spaces during certain time of day by requiring vehicles to display a sticker that can only be obtained by the residents. The conditions include that at least $80 \%$ of the occupied frontage is residential use, at least $85 \%$ of on-street parking spaces are occupied during the time period for which the permit is requested, and less than $45 \%$ of the parked vehicles belong to the area residents. The Municipal Code (9) also designates parts of the downtown as restricted parking areas where commercial vehicles are not allowed to park except in designated loading zones for loading, unloading, and delivery activities. While the street signs indicate the areas where these restrictions are in place, it is difficult for the drivers who are not familiar with the area to know how far the restricted zone extends or where to find unrestricted parking spaces.

When snow accumulation exceeds 2 inches $(5.1 \mathrm{~cm})$, certain designated "snow routes" become noparking streets in order to provide room for the snow removing vehicles to operate. Violation of this snow route parking rule, combined with street cleaning and special events account for $6.7 \%$ of citations (Table 1). Interestingly, only a small number of tickets are given for double-parking, which Han et al (2) 
identified as one of the leading causes of urban non-recurring congestion. It should be noted that most double-parked trucks are engaged in loading/unloading activities. As such, double parking may not be cited by the parking enforcement officers as long as it is kept short although it is a violation of the traffic code no matter how short the duration may be. In fact, during a field observation, we witnessed an onduty parking enforcement officer walk past a double-parked parcel delivery truck without issuing a ticket.

TABLE 1 Breakdown of Truck Parking Citation Types (September 1, 2011 - August 31, 2012)

\begin{tabular}{|l|l|l|l|}
\hline Violation type & Sum of Fines (\$) & Citations & \% of total citations \\
\hline Vehicle Type Prohibited & $\$ 1,041,425$ & 37,145 & $29.5 \%$ \\
\hline No Parking Zone & $\$ 1,520,050$ & 22,193 & $17.6 \%$ \\
\hline Expired Meter & $\$ 837,350$ & 16,221 & $12.9 \%$ \\
\hline Plate violation & $\$ 902,055$ & 15,043 & $11.9 \%$ \\
\hline Parking Permit & $\$ 1,939,665$ & 13,297 & $10.6 \%$ \\
\hline $\begin{array}{l}\text { Street Cleaning, Snow, } \\
\text { Special Event }\end{array}$ & $\$ 423,920$ & 8,414 & $6.7 \%$ \\
\hline Block Access & $\$ 663,260$ & 5,254 & $4.2 \%$ \\
\hline Bus Lane or Stop & $\$ 271,900$ & 2,746 & $2.2 \%$ \\
\hline Fire Hydrant/Lane & $\$ 196,000$ & 1,938 & $1.5 \%$ \\
\hline Double Parking & $\$ 163,200$ & 1,632 & $1.3 \%$ \\
\hline Equipment* & $\$ 130,800$ & 919 & $0.7 \%$ \\
\hline Curb Loading Zone & $\$ 27,000$ & 450 & $0.4 \%$ \\
\hline Disabled Parking & $\$ 71,800$ & 359 & $0.3 \%$ \\
\hline Operation* & $\$ 27,850$ & 217 & $0.2 \%$ \\
\hline Seatbelt* & $\$ 4,175$ & 167 & $0.1 \%$ \\
\hline Improper Parking & $\$ 1,300$ & 26 & $0.0 \%$ \\
\hline Unattended Vehicle & $\$ 1,125$ & 15 & $0.0 \%$ \\
\hline Grand Total & $\$ 8,222,875$ & 126,036 & \\
\hline
\end{tabular}

* Not included in the hot spots and regression analysis

Figure 1 shows the 14-day moving average of truck parking citations over a period of 12 months spanning from September 1, 2011 to August 31, 2012. The figure indicates that the frequency of truck parking violations in Chicago is relatively constant throughout the year, although July through December seems to represents a moderate peak. There is a noticeable drop in the frequency in December, possibly due to "parking meter holidays" for the Christmas and New Year's Day and also somewhat lenient enforcement during those critical time periods for the businesses.

Figure 2 depicts the frequency of citations by day of the week. Not surprisingly, violations during the weekends are significantly lower. An analysis of the frequencies of passenger vehicle parking citations also reveals a similar pattern. While traffic volumes on Chicago streets are quite high on weekends, the lower number of citations can be attributed to the lower level of enforcement over the weekends rather than a decrease in the frequency of violations.

Figure 3 depicts the time-of-day distribution of parking tickets. The peak period for trucks to receive parking citations begins around 7am, reaching the peak around 9:30am, and continuing till 10:30am. Although there is no reliable 24-hour truck counts in the city, this pattern largely coincides with the peaking of truck activities that truck operators identified through past interviews by the authors of this paper. Many of the truck deliveries are made before 9 AM, specifically between 7 am and 8:30am, or after 9 AM, between 9:30am and 10:30am, the peak of morning rush. Truck activities in the city are 
mostly over by $4 \mathrm{pm}$ and the citation rate decreases to a negligible level thereafter. For passenger vehicles, the citation rate decreases more gradually.

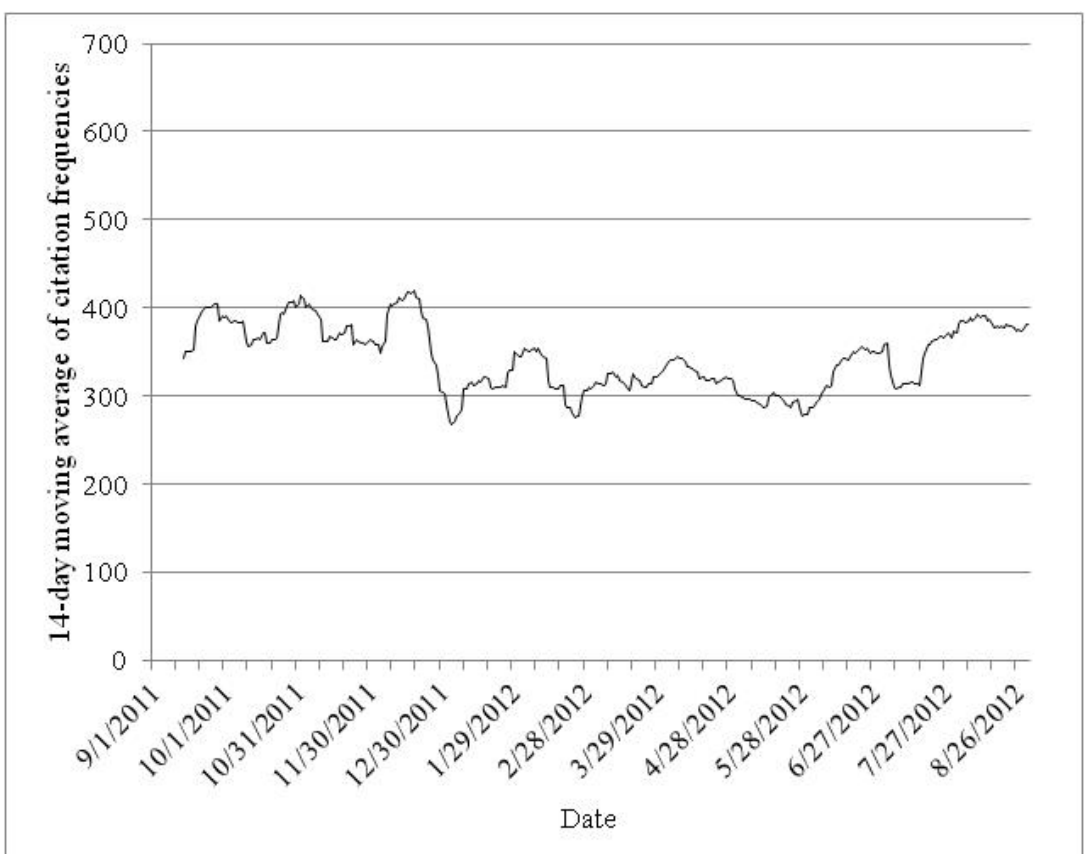

FIGURE 1 Truck Citation Frequency over One Year (September 1, 2011 to August 31, 2012)

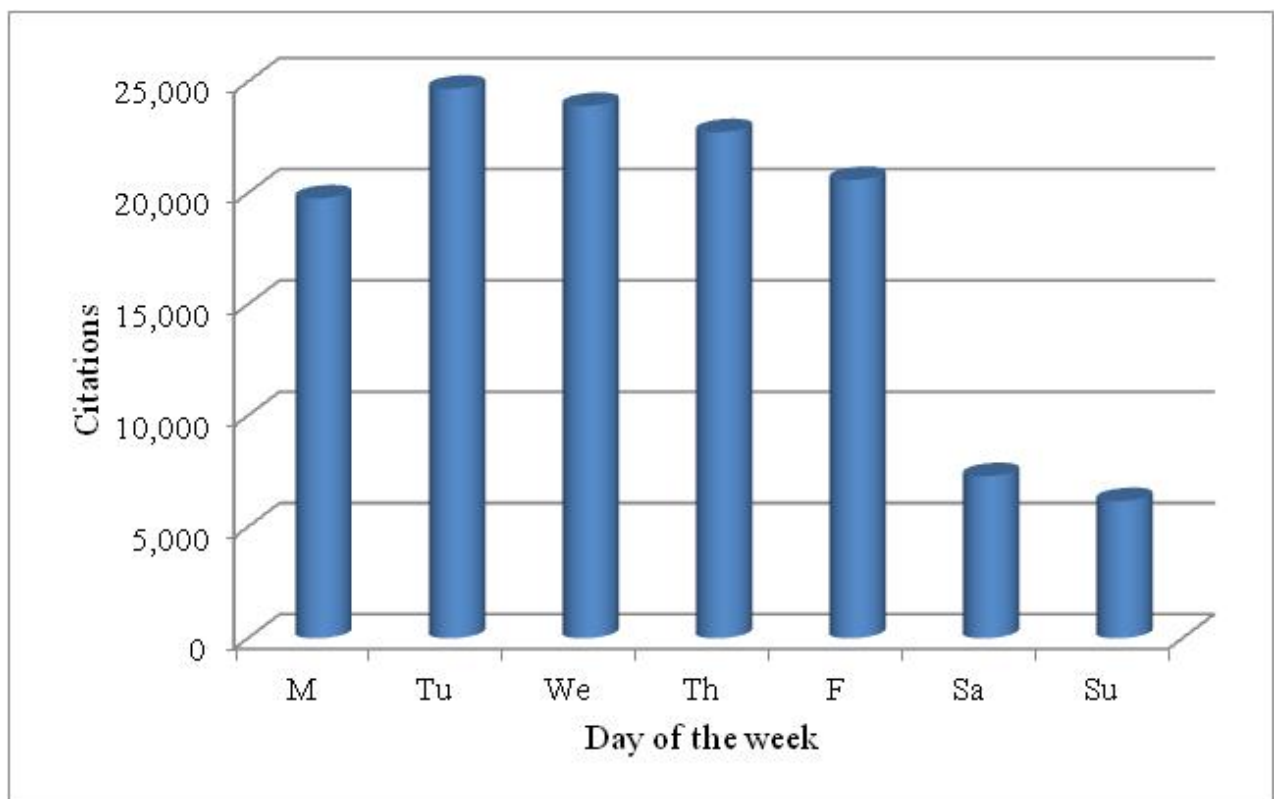

FIGURE 2 Day of the Week Distribution of Truck Parking Citations (September 1, 2011 to August 31, 2012) 


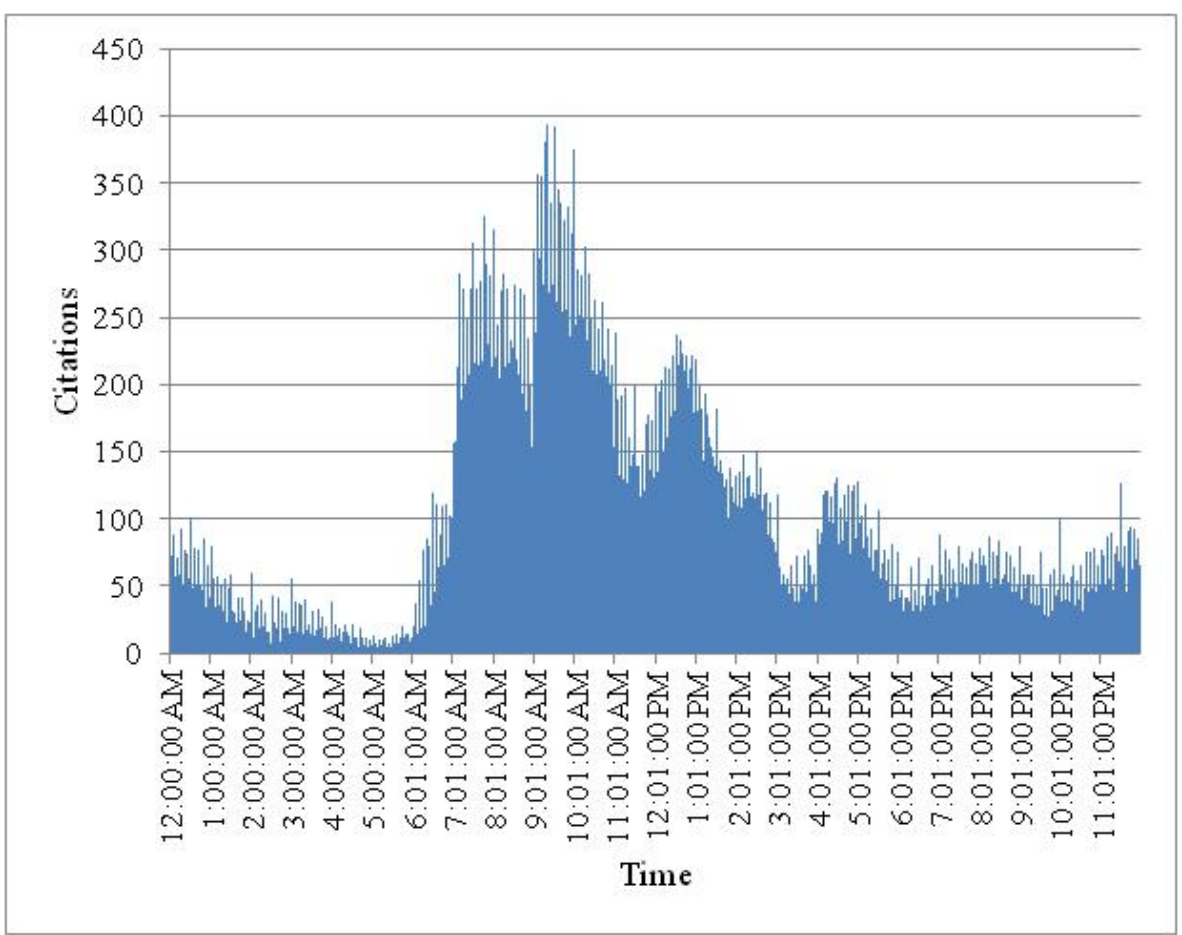

FIGURE 3 Time of Day Distribution of Truck Parking Citations (September 1, 2011 to August 31, 2012)

\section{ANALYSIS}

\subsection{Hot Spot Analysis of Truck Citation Density}

The variable of interest for this part of the study is the density of truck parking violations, calculated at the Census block group level. Each block group contains between 600 and 3,000 residents, with the optimum value of 1,500 people (10). As such, the sizes of block groups vary significantly across an urban area. The average size of block groups for the study area is $0.27 \mathrm{~km}^{2}$ (approximately 0.1 square mile).

Getis-Ord G statistics is commonly used to identify "hot spots" where unusually high or low levels of observations (parking violations in this case) are clustered in some areas (11). G statistic is calculated by

$$
G_{i}(d)=\frac{\sum_{j} w_{i j} x_{j}}{\sum_{j} x_{j}}
$$

where, $G i(d)$ is the $\mathrm{G}$ statistic calculated for location $i, x_{j}$ is the variable of interest observed for location $\mathrm{j}$, $w_{i j}$ is the spatial weight metrics that is 1 if $j$ is within a predefined distance, $d$, from $i$, and zero otherwise. The numerator is the sum of the $x$ values for all the zones that are within $d$ from $\mathrm{i}$, and the denominator is the sum of all the $x$ values in the data set. Thus, Gi(d), is simply the proportion of $x$ values that are neighbors, which is defined by the analyst according to a rule, of location $i$ with respect to the sum of all $x$ values in the study area. Getis and Ord showed that under most conditions, Gi(d), is asymptotically normal, and thus hypothesis tests can be performed using z-test (with the null hypothesis being spatial independence of the $x$ variable). 
Figure 4 shows the hot and cold spots identified using the standardized (in Z-value) Getis-Ord G statistic. Positive and negative $G$ statistic indicate the areas with higher or lower than expected density of truck parking violations, respectively.

Figure 4 shows the downtown (CBD) and the area immediately north (Magnificent Mile and Gold Coast neighborhoods) as the focal area of the most intense concentration of violations. The CBD, known as the "Loop" and the area to the north are the centers of commercial activities and the finding is not surprising. Also, there are additional areas that form the bands of high-violation areas. They are 1) the corridor stretching along Lake Michigan to the north of the CBD, 2) the area along Interstate 90/94 that leads toward O’Hare Airport, and 3) areas along Interstate 55 heading southwest. The first area is a mix of dense residential areas with commercial businesses. The second area is comprised of residential, commercial, and some industrial neighborhoods. The third area includes mostly industrial developments that go back to the early days of Chicago, which still enjoys excellent access to the rail network and is home to truck terminals, warehouses and rail yards. The figure also shows that the density of parking violations decreases gradually toward the periphery of the city. However, there is a pocket of neighborhoods near the CBD just south of the downtown that is shown to be neither hot nor cold spot. While this area is home to numerous distribution centers and rail yards, roads are designed to accommodate large trucks and land use resembles suburban industrial parks. While more research will be needed to determine the relationship between the parking violation density and road design and land use, it is clear that the stress level for trucks, as far as parking is concerned, seems to be much lower than at other areas near the downtown.

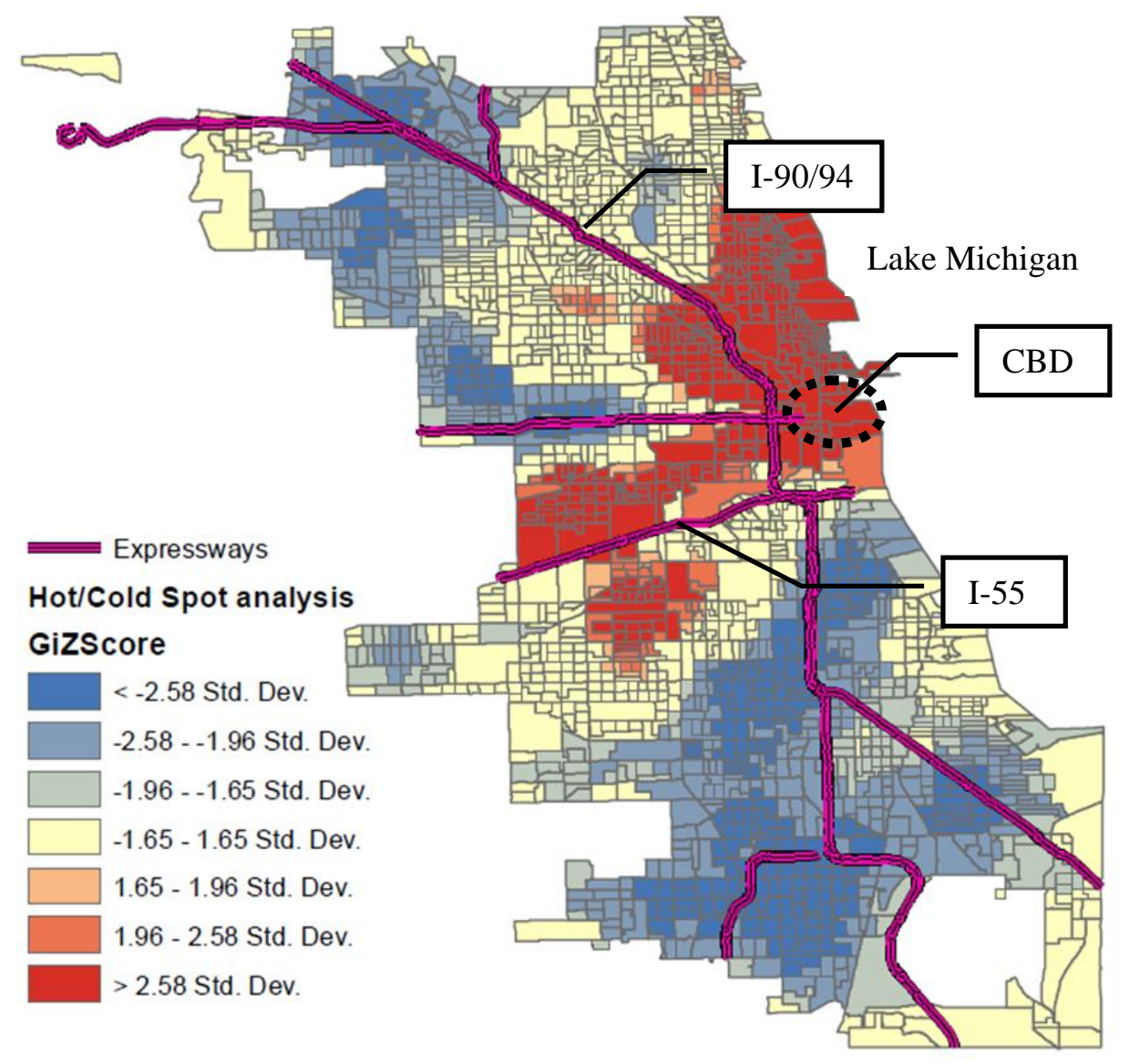

FIGURE 4 Truck Citation Density Hot and Cold Spots (July and August 2012) 


\subsection{Regression Analysis}

While the previous analysis identified areas that see high or low density of parking violations by trucks, we need to carry out more detailed analysis to identify the factors that explain the differences among those areas. The analysis in this section examines the relationship between the number of truck tickets given within each block group and various socioeconomic and built environment factors to explain the variation in the former.

As described in the Data section, both public and proprietary databases were available to compile a large number of potential independent variables. To include all of the variables, more than 100 in total, in the regression analysis is not feasible nor appropriate since many do not present intuitive or theoretical connection with truck delivery activities or parking violations. Subsequently, the analysis focused on three types of variables: 1) indicators of economic activities that are known to generate truck traffic, 2) socioeconomic characteristics of residents, and 3) built environment.

Independent variables include

- number of establishments and employment at the NAICS 2-digit level

- combined employment in professional services (NAICS 54), finance and insurance (NAICS 52), and information (NAICS 51) sectors

- median household income

- population density

- housing unit density

- total retail sales

- total merchandise sale

- total sales from food services

- average annual residential turnover rate

- average vehicle per household

- vehicle density

- work trip transit mode share

- housing stock occupancy rate

- median age of residential structures

- shares of housing units across various building sizes (single detached, duplex, 3-9 units buildings, etc.)

- participation rate in on-line shopping

- average rents and average house values

- median age of residents

- average household size

- density of alleyway

- average parcel size

- density of passenger parking citations

- total length of street curbs.

The densities are calculated based on the area of each block group except for the passenger vehicle parking citations, which is calculated based on the total curb length within each block group. Alleyways or alleys are narrow service lanes that run behind buildings. They are often used by garbage collectors and in some cases, provide access to the parking spaces behind the building. The last variable, total length of street curbs, is used as the exposure variable. As such, the parameter estimate is constrained to 1 and its role is to convert the dependent variable, number of truck parking citations, into the density of citations per $\mathrm{km}$ of street curb. This approach would provide accurate information on the distribution and intensity of parking violations since it control for the exposure level, i.e. the block groups with longer total curb lengths would collect more parking violations. 
It is reasonable to assume that greater amount of resources are allocated to enforce parking regulations in the areas with more frequent violations. In other words, it is quite plausible that the intensity of enforcement efforts is not uniform across the block groups. Since over $80 \%$ of parking citations are given to passenger vehicles, it can be further assumed that spatial distribution of parking violations by passenger vehicles dictates the city's allocation of parking enforcement officers. As such, we used the density of tickets given to passenger vehicles to account for the variation in the intensity of enforcement efforts. The descriptive statistics for the independent variable, the number of truck parking tickets, are shown in Table 2 .

\section{TABLE 2 Descriptive Statistics of the Dependent Variable}

\begin{tabular}{|l|r|}
\hline \multicolumn{2}{|l|}{$\begin{array}{l}\text { Total number of truck parking citations } \\
\text { per block group for July and August } \\
2012\end{array}$} \\
\hline Mean & 8.14 \\
\hline Median & 4.00 \\
\hline Std. Deviation & 26.5 \\
\hline Skewness & 25.5 \\
\hline Minimum & 0 \\
\hline Maximum & 917 \\
\hline
\end{tabular}

Since the independent variable is a count variable with a high level of skewness, generalized linear models such as Poisson or negative binomial, instead of linear regression, are more appropriate for analyzing this data set. Use of Poisson regression implicitly assumes that the variance and mean of the dependent variable are the same, which is not the case for this data set. As such, we used negative binomial regression with a log link function.

Negative binomial regression assumes that the dependent variable, $Y$, is distributed with $Y \sim N B(\mu, \theta)$ where

$$
\begin{aligned}
& \mathrm{E}(\mathrm{Y})=\mu \\
& \operatorname{Var}(\mathrm{Y})=\mu+\theta \mu^{2}
\end{aligned}
$$

and NB( ) denotes negative binomial distribution.

Negative binomial accounts for overdispersion, the amount of variance over the mean (i.e. compared with the Poisson distribution), with the term $\theta \mu^{2}$. As noted in ver Hoef and Boveng (12) and obvious from the equation 3, the overdispersion in negative binomial is expressed as quadratic of the mean. In negative binomial regression, in addition to the parameters of the independent variables, the dispersion parameter, $\theta$, needs to be estimated. 
The model is constructed using only the parameters that are statistically significant at the $5 \%$ significance level. Density of passenger vehicle citations was transformed with square root to address the multicollinearity issues with other independent variables.

The final model results are shown in Table 3 . The fit of the model is satisfactory with a very strong result for the overall test of fit using the log-likelihood ratio test. Pseudo R-square, which is a proportional reduction in the log likelihood compared against the intercept-only model, is reasonable for this type of model. The estimate of the dispersion parameter is below 1, indicating a relatively mild overdispersion. It should be noted that negative binomial regression is not the only approach to analyze this data set. Other plausible techniques include zero-inflated Poisson and quasi-Poisson regressions. Selecting an approach is largely subjective since there is no definitive test or performance indicator for selecting among different approaches. In the case of this analysis, diagnostics indicated a good fit with negative binomial model, and thus other approaches were not pursued.

\section{TABLE 3 Regression Results}

\begin{tabular}{|c|c|c|c|c|c|c|}
\hline \multicolumn{7}{|c|}{$\begin{array}{l}\text { Dependent variable: JulyAug_TRK (Truck parkin } \\
\mathrm{N}=2172 \\
\text { LR Chi-Sq }=11,614(\mathrm{df}=8, \mathrm{P}=0.000) \\
\text { Pseudo } \mathrm{R}^{2}=0.137 \\
\text { AIC }=72,973 \\
\text { Scale variable: Road km (Total curb length in } \mathrm{km} \text { ) }\end{array}$} \\
\hline $\begin{array}{l}\text { Independent } \\
\text { variable }\end{array}$ & Description & $\begin{array}{l}\text { Coefficient } \\
\text { estimates }\end{array}$ & $\begin{array}{l}\text { Standard } \\
\text { Error }\end{array}$ & $\begin{array}{l}\text { Wald } \\
\text { Chi-sq }\end{array}$ & p-Value & Elasticity \\
\hline Intercept & & $9.86 \mathrm{E}-01$ & $2.65 \mathrm{E}-02$ & 1,388 & 0.000 & \\
\hline RT_PAX_den & $\begin{array}{l}\text { (Passenger citations } \\
\text { density per km of curb) } \text { ) }^{-1 / 2}\end{array}$ & $3.34 \mathrm{E}-01$ & $5.34 \mathrm{E}-03$ & 3,920 & 0.000 & 0.160 \\
\hline Man_eden_K & $\begin{array}{l}\text { Manufacturing } \\
\text { employment density per } \\
\mathrm{km}^{2} \text { in } 000 \mathrm{~s}\end{array}$ & $2.20 \mathrm{E}-03$ & $5.78 \mathrm{E}-04$ & 14 & 0.000 & 0.000 \\
\hline Alley_dens & Alley density per $\mathrm{km}^{2}$ & $-1.16 \mathrm{E}-03$ & $1.33 \mathrm{E}-04$ & 75 & 0.000 & -0.023 \\
\hline AVG_Parce & Average parcel size in $\mathrm{ft}^{2}$ & $2.72 \mathrm{E}-04$ & $1.23 \mathrm{E}-05$ & 488 & 0.000 & 0.001 \\
\hline veh_den & $\begin{array}{l}\text { Density of vehicles } \\
\text { owned by residents per } \mathrm{ft}^{2}\end{array}$ & $-1.24 \mathrm{E}+02$ & $5.81 \mathrm{E}+00$ & 455 & 0.000 & -0.053 \\
\hline turnover & $\begin{array}{l}\text { Annual } \\
\text { residential } \\
\text { turnover rate in } \\
2011\end{array}$ & $1.39 \mathrm{E}-02$ & $1.35 \mathrm{E}-03$ & 106 & 0.000 & 0.027 \\
\hline food_sal & $\begin{array}{l}\text { Sales at food serving } \\
\text { establishments }(\$)\end{array}$ & $2.08 \mathrm{E}-05$ & $1.28 \mathrm{E}-06$ & 267 & 0.000 & 0.006 \\
\hline $\begin{array}{l}\text { onl_s } \\
\text { hop }\end{array}$ & $\begin{array}{l}\text { Percentage of } \\
\text { households that } \\
\text { made on-line } \\
\text { purchase in last } \\
30 \text { days }\end{array}$ & $-3.05 \mathrm{E}-03$ & $4.25 \mathrm{E}-04$ & 52 & 0.000 & -0.031 \\
\hline Dispersion $(\theta)$ & Dispersion parameter & 0.640 & & & & \\
\hline
\end{tabular}

Since the model is estimated using log link function, the parameter estimates were converted into elasticities evaluated at the mean to interpret the results, which is a standard practice for this type of 310 model. The greatest elasticity is for RT-PAX-den, suggesting that there is a strong association between 
parking violations by regular travelers and trucks. This can be interpreted as the effects of the level of enforcement and also the overall demand for parking in the neighborhood. Of all the employment and business establishment variables, only the manufacturing employment density, "Man_eden_K" was found to be significant. It should be noted, however, that the effect is extremely modest as the elasticity is close to zero.

Meanwhile, sales at food-serving establishments was found to increase truck parking violation, albeit at a relatively modest level. Higher rate of residential turnover would result in modest increase in parking citation rate, suggesting that stability in neighborhoods is associated with lower incidents of parking violation. Surprisingly, lower density of vehicles owned by the residents actually increase truck parking violations. This may be due to the fact that the areas with most frequent violations are generally found in the neighborhoods that enjoy high level of transit service. In fact, transit mode share was found to have the same effect as the vehicle ownership. The areas with high transit mode share tend to experience higher density of truck parking citations.

According to the model, the presence of ample alleyways reduces parking violations by trucks, although the effect is modest. Average parcel size, which is an indicator of building footprint, has extremely modest positive effect on parking citations. High rate of participation in on-line shopping has negative effect on violations. Although it will require further research to confirm, this may be attributed to the reduction in the frequency of trips made by the residents and/or consolidation of deliveries that occurs when the parcel delivery companies make deliveries of on-line shopping items from different vendors. Another possible explanation is that people who participate in on-line shopping may prefer certain types of neighborhoods that provides, for example, ample loading/unloading zones or off-street parking spaces.

Perhaps, the most intriguing aspect of the model results is that variables such as employments in freight intensive industries such as transportation/warehousing and wholesale were not statistically significant explanatory variables. This underscores the fact that the overwhelming majority of trucks in any urban area are not directly associated with heavy industries or transportation businesses. In fact, truck surveys conducted in French cities and Tokyo have found that businesses such as cafes, restaurants, and hotels typically generate several times more truck trips than warehousing or industrial land uses. Also, as mentioned earlier, generous street design in the industrial areas within the city may be another contributor for keeping the truck parking violation rates low in those neighborhoods.

\section{CONCLUSIONS}

This study examined the relationship between spatial distribution/concentration of parking violations involving trucks and various socioeconomic and built environment factors. We found that nearly $40 \%$ of parking citations examined in this study can be attributed to truck bans, either for specific types of roads or designated neighborhoods. While the bans allow trucks to be parked during the loading and unloading activities, delivery schedules, often dictated by the receiver, require trucks to do a lot of waiting between deliveries. It may be worthwhile to create an on-line map of the streets and neighborhoods with truck bans that the drivers can use to find the areas where they can do the waiting legally.

Hot spot analysis was conducted using the Getis-Ord statistic. The analysis showed that parking problems were generally worse within or near the downtown and become less prevalent toward the outer perimeter of the city. However, it was also found that truck parking did not seem to be a serious issue in the part of the city that has been home to industrial sites for a long time. Most likely, this is due to the combination of street design and low building density that are contributing to the reduced level of parking problems in the area. 
To investigate the relationship between specific socioeconomic and built environment factors and prevalence of parking violations by trucks, the rate of truck parking violations was regressed against various socioeconomic and built environment variables. The analysis indicated that areas with high level of food-service sales and low density of vehicles tend to experience higher rate of violations. High residential turnover rate was also found to increase parking citations. Taken together, the profile of the areas with truck parking problems fit those of vibrant, newly developed, mixed-use neighborhoods with low vehicle density. On the other hand, it was found that industrial and transportation businesses were not associated with high levels of truck parking violations. Thus, the analysis seems to indicate that the both supply (i.e. provision of parking and street design) and demand affect the level of truck parking violations. While this is not a surprising result, the finding underscores the importance of land use plan and urban and streetscape designs that takes into account delivery trucks in the neighborhoods that may not seem to generate intense truck activities. The research also revealed that alleys could alleviate some of truck parking problems although their effect is relatively modest.

The findings described in this paper can serve as the basis for formulating several potential hypotheses that can be examined in future studies. First, overall level of demand for parking from all types of vehicles including passenger and service vehicles engaged in a wide-range of activities, not necessarily industrial, contributes to the level of truck parking problems in the neighborhoods. Second, some aspects, possibly streetscape and parking regulations, of newer mixed-use neighborhoods tend to create issues for trucks. And third, off-street parking spaces that can be accessed via alleys are moderately effective in alleviating truck parking problems. It is important to conduct a detailed examination of how the trucks are using alleys.

It will require more fine-grained analysis, perhaps examining specific types of violations and interviewing truck operators, to obtain necessary information to formulate an effective analysis framework to empirically test these hypotheses and fully understand the underlying factors that affect parking problems for trucks and develop a set of strategies to alleviate them.

\section{ACKNOWLEDGEMENT}

This work was partially funded by the National Center for Freight and Infrastructure Research and Education (CFIRE) based at the University of Wisconsin and Illinois Department of Transportation as well as Metropolitan Transportation Support Initiative (METSI) at Univeristy of Illinois at Chicago. CFIRE is a national university transportation center supported by the US Department of Transportation.

\section{References}

1. Han, L. et al. (2005) "Estimating the Impact of Pickup- and Delivery-Related Illegal Parking Activities on Traffic". Transportation Research Record 1906. Transportation Research Board, 2005

2. Pivo, G. (2002) "Learning from Truckers: Truck Drivers' Views on the Planning and Design of Urban and Suburban Centers". Journal of Architectural and Planning Research. Spring, 2002.

3. US Department of Transportation. (2009) Urban Freight Case Studies: Washington, D.C.

4. M. Jaller, J. Holguin-Veras, and S. Hodge. (2013). "Parking in the City: Challenges for Freight Traffic" Proceedings of the 92nd Transportation Research Board Annual Meeting. Washington DC. 
5. Holguín-Veras, J., et al., (2011). Freight Generation, Freight Trip Generation, and the Perils of Using Constant Trip Rates. Transportation Research Record 2224: p. 14.

6. Lawson, C., et al., (2012). Estimation of Freight Trip Generation Based on Land Use. Proceedings of the 92nd Transportation Research Board Annual Meeting. Washington DC.

7. A. Conway, O. Thuillier, E.Dornhelm, N. Lownes. (2013). "Commercial Vehicle-Bicycle Conflicts: A Growing Urban Challenge" Proceedings of the 92nd Transportation Research Board Annual Meeting. Washington DC.

8. Schrank, D. W. Eisele, and T. Lomax. 2012 Urban Mobility Report. Texas A\&M Transportation Institute. Texas A\&M University. College Station. TX.

9. City of Chicago. Municipal Code of Chicago. American Legal Publishing Corporation. Cincinnati, OH. June 2013.

10. US Census Bureu (2013) "Geographic Terms and Concepts - Block Groups"

http://www.census.gov/geo/reference/gtc/gtc_bg.html US Census Bureau.

11. Ord, J.K. and Getis, Arthur (1995). "r;Local Spatial Autocorrelation Statistics: Distributional Issues and an Application." Geographical Analysis 27, 286-306.

12. Ver Hoef, J.M. and P. Boveng. (2007) Ecology,88(11),pp.2766-2772, Ecological Society of America 